\title{
معوقات انتشار رياضة الجمباز بصعيد مصر
}

\section{كريمة عبدالباسط حسين جادو}

\section{المقدمة ومشكلة البحث :-}

يتميز العصر الحديث بالتقدم العلمى الذى يغزو جميع المجالات ويتسـابق العلماء والباحثون لتطبيق احدث الاساليب العلمية للتغلب على ما يعترض مسيرة التقدم من مشكلات ووسيلتهم فى ذللك الدراسة العلمية والبحث فى جميع المجالات . ورياضــة الجمبـاز هـى احدى انـواع الانشـطة الحركيـة والتـى تتميـز بتأثيرهـا

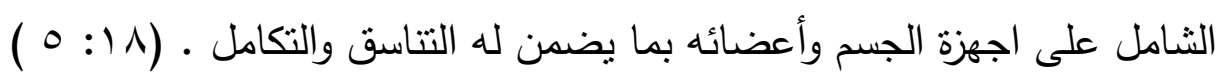
ورياضــة الجمبـاز مـن الرباضـات الفرديـة ولها تـاثير فعـال فـى كفاءة وحيويـة

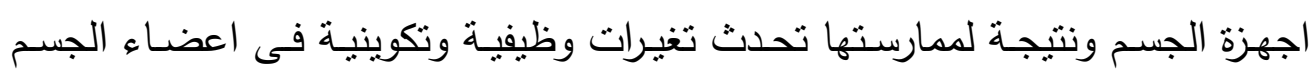
واجهزته خاصة الجهازين الحركى والعصبى والمقصود بهذا التغير والتحسن فى اجهزة الجسم هو التكيف البيولوجى الذى يحدث نتيجة لممارسـة الجمباز ، وللجمباز اهميـة خاصـة كرياضـة فهو يعتمد على التوافق والمهارة وينمى الكثير من الصفات العقلية كاليقظة والجراة والدقة ، كما ان كثير من حركات ومهارات الجمباز تستدعى التقكير السريع وحسن التصرف ، وهو بهذه الصورة يشكل عمليـة متكاملة لتتميـة الفرد بدنيا

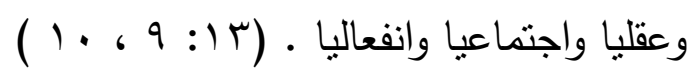

وتظهر اهمية رياضـة الجمباز فى برامج التربية الرياضية ، من خـلال اشباع

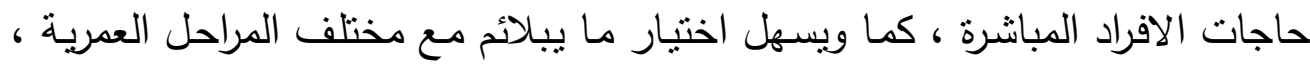
مثل جمبـاز الالعـاب لريـاض الاطفـال ، وجمبـاز الموانـع لجميـع الاعمـار ، وجمبـاز

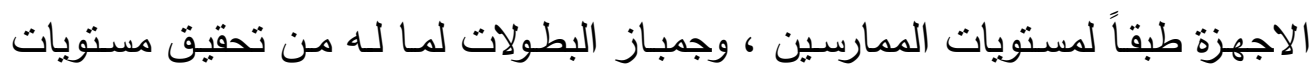
عالية من الكفاءات والقدرات ، وتحقيق الدرجات العالية من المنافسات ، وكما ان هنالك

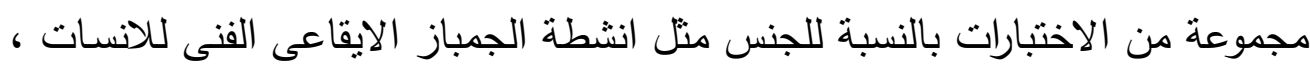


وانشطة الجمباز الفنى الزوجى والجمـاعى والاكروبـات الارضـى للرجـال ، ومـن هذا المعنى يمكن اعتبار رياضـة الجمباز احد الرياضات الاساسية التى تساعد الفرد على

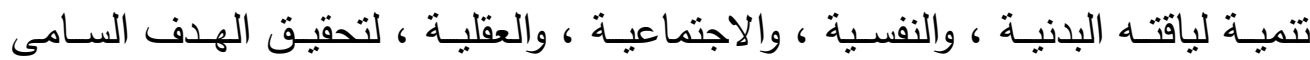

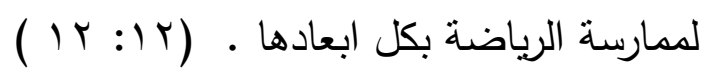

ان حركات الجمباز هى تمارين اساسية ومساعدة لانواع الرياضـة كافة ، فنجد على سبيل المثال ان الدحرجة الامامية هى تمرين اساسى لكثير من الالعاب الرياضية

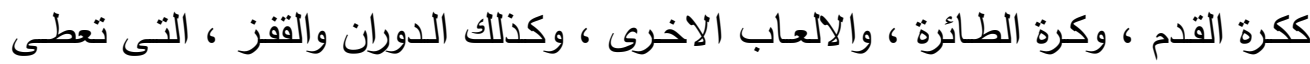

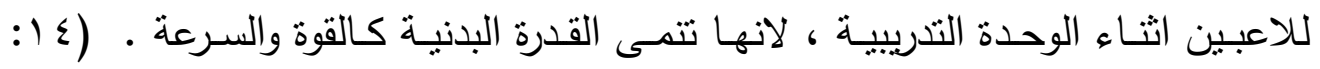

ونظراً لاهمية رياضة الجمباز اخذت الدول على عاتقها الاهتمام بهذه الرياضـة

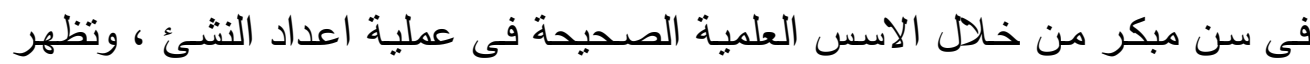
اهمية دراسة المعوقات لرياضة الجمباز للطلاب فى مرحلة التعليم المبكر ، وايضا كافة المراحل العمرية ، لانها تحتوى على تمارين رياضية كثيره ، ولان هذه الرياضة واسعة هرهة الانتشـار ، فهى تمـارس فى المدارس والجامعـات ، ولقضـاء اوقات الفراغ والتسـلية . (or: :17)

ان عملية تدربب الجمباز تتطلب الاعداد لسنوات عديدة حتى يصل اللاعب لمستوى مرموق ، والاعداد لعدة سنوات لا ياتى جزافاً ، وانما ياتى عن طريق التخطيط

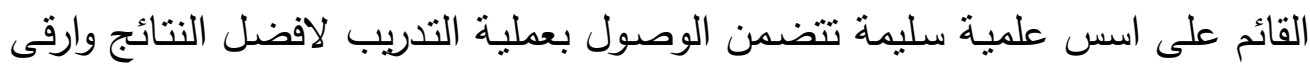

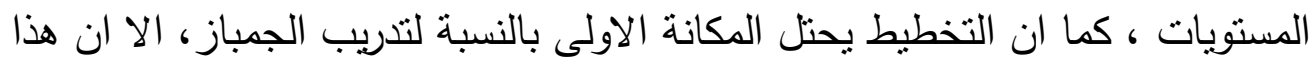

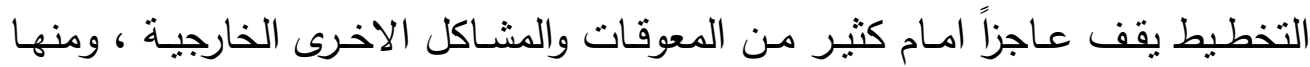
مشاكل خاصة بالتدريب.( • (1 : (1) ان هنـاك مجموعـة مـن العوامل والمعوقات المرتبطـة بالرياضــة مثل الظـروف التى يعيش فيها اللاعب والمدرب وهى ليست وثثقة الصلة بشكل مياشر باللاعب او المدرب ولكنها وثثقة الصلة بمجموعة عوامل اجتماعية واقتصـادية تؤثز على عملية 
التدريب مثل الحالة المالية ونظرة الاسرة للجمباز وموقفهم من ممارسة ابنهم (اللاعب)

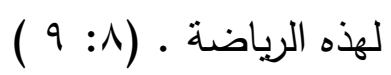

لاحظت الباحثة كثير من المعوقات التى تحول ظهور هذه اللعبة فى صعيد مصر من قلـة الامكانيات الماديـة والبشرية والنظرة السلبية للاسرة فى ممارسـة ابنائها

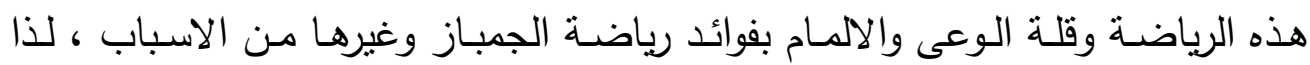
تقترح الباحثة البحث فى ذلك الموضوع وهو معوقات رياضة الجمباز فى صعيد مصر للوقوف على هذه الاسباب ومحاولة ايجاد حلول لها . اهمية البحث والحاجة البه :-

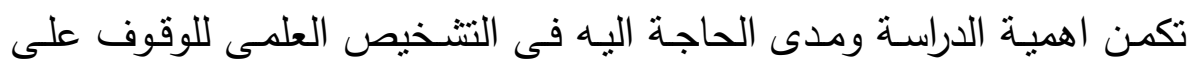
المعوقات التى تعترض ظهور وتقدم منل هذه الانشطة .

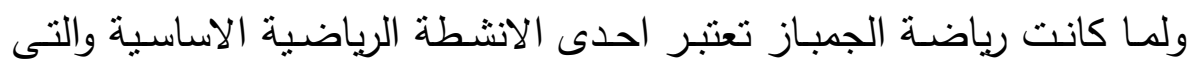

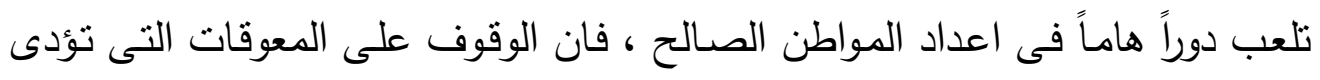
الى عدم تقدم هذا النوع من النشاط فى الصعيد من جهه وعدم انتشاره بين الثباب من الثن جهة اخرى لذا ترى الباحثة ان لهذه الدراسة اهمية خاصة .

$$
\text { تتحصر ألبحدث :- }
$$

1. التعرف على اهم المعوقات التى ادت الى عدم ظهور وانتشار رياضة الجمباز

$$
\text { فى صعيد مصر . }
$$

r. التعرف على الاهمية النسبية لهذه المعوقات على ظهور وانتشار رياضة الجمباز

$$
\begin{aligned}
& \text { فى صعيد مصر . } \\
& \text { تساؤلات البحث :- }
\end{aligned}
$$

1. ما المعوقات التى تحول دون ظهور وانتشار رياضة الجمباز فى صعيد مصر؟ 
r. ما الاهمية النسبية لكل معوق من هذه المعوقات على ظهور وانتشار رياضـة

الجمباز فى صعيد مصر؟

\section{بعض المصطلحات الواردة بالبحث :-

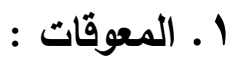

الصعوبات والمشكلات التى تواجه المدرس وتمنعه من توظيف كافة امكاناته

$$
\begin{aligned}
& \text { وقدراته التعليمية ـ ( Y : ) } \\
& \text { r. الجمباز : }
\end{aligned}
$$

هو عبارة عن نشاط رياضى فردى مكون من مجموعة من الحركات والمهارات التى تمتاز بالقوة والرشاقة والمرونة وتكون على شكل سلسلة من الحركات على جهاز معين وتؤدى ضمن قوانين وقواعد محددة. (r)

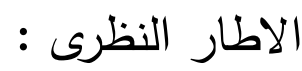

تم بنـاء الاطـار النظرى بـالرجوع الـى المراجـع العربيـة والاجنيـة والدراسـات والابحاث المنشورة ، وقد تتـاول الاطـار النظرى موضـوعات رياضـة الجمباز واهميتها والمعوقات التى تواجه هذه الرياضة فى صعيد مصر وذللك على النحو التالى :

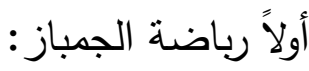
تعتبر رياضة الجمباز من الانشطة الراضية الهامة فى المجال تتضمن العديد

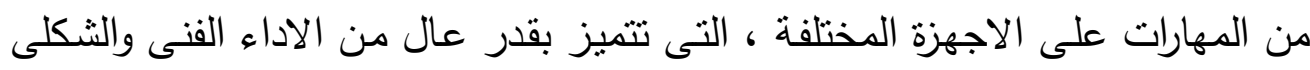
والذى يعتبر احد العواملـل الرئيسية المؤديـة الى تحقيـق الفوز بـالبطولات ـ ( 19 :

لقد اثتت رياضة الجمباز انها الرياضة النموزجية لكافة الاعمار ، لانها تحتوى على تمارين رياضية كثيرة جداً ، وهذه التمارين ذات خصوصية لتتمية القدرات البدنية والعقليـة ، اذ ان ممارسـة رياضـة الجمبـاز اليوم واسـعة الانتـــار ، فهـى تمـارس فـى المدارس والجامعات ، ومؤسسات الدولة الاخرى كالجيش والثرطة ، بالاضـافة الى ان 
تمـارين راضـة الجمبـاز تعد تمـارين ترويحيـة لقضـاء اوقات الفراغ والتسـلية ( 10 :

يتميز الجمبـاز بتـاثيره الثـامل على اجهزة الجسـم واعضـاءه بمـا يضـمن لـه التتاسق والتكامل ، كما انه يساعد على تتمية التوافق العضلى العصبى ، ويعمل على الى تيسير تحكم الفرد فى جسمه وحركته ، ومن جهة اخرى يعمل الجمباز على الموازنـة ومعالجة الاوضـاع الجسمانية الخطا التى اوجدتها ظروف الحياة الصعبة . ) ( 0 ( ) ( I Y فالى جانب كونها من الرياضات الاساسية فان لها اسهامات فى رفع مستويات

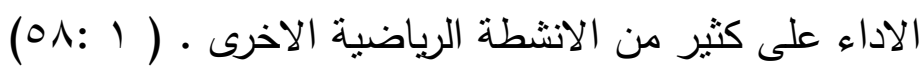

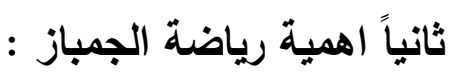
يعتمد تغلب مدربى الالعاب الرياضية على اجهزة الجمباز ، كاجهزة مساعدة فهى تسهم فى اعداد اللاعبين ، وتطوير مستوياتهم دن خلال التمارين على الاجهزة ، كما انها تتمى لدى اللاعب النواحى الجسمية والعقلية والتربوية ، ويمكن تحديد اهمية

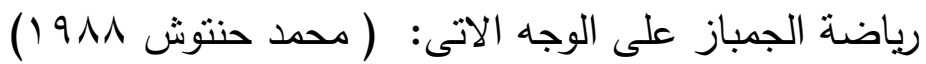
ا. الصـحة العامـة : من خـلال ممارسـة رياضـة الجمبـاز بمكن نوجيـه اللاعبين صـحياً الـى اتبـاع النواحى والقواعد الاساسـية للصـحة العامـة ، ومـن خـلال التدريب اليومى يمكن الحفاظ على صحة الجهاز التنفسى ، وجهاز الدوران ، والجهاز العصبى ، وان صحة الاجهزة الداخليـة لجسم الانسان يمكن الحفاظ عليها من خـلال تتظيم الحياة اليوميـة فممارسـة الجمباز تسـاعد على تحسين وتتظيم حياة الفرد اليوميـة من خـلد استغلال اوقات الفراغ بالتدريب المنظم الاسبوعى ) r. تثمية اللياقة البذنية : يساعد الجمباز كبقية الالعاب الرياضية الاخرى على تتمية اللياقة البدنية ( القوة والسرعة والمرونـة والرشـاقة والمطاولة ) فمن خلال 
التـدريب تصبح اجهزة الجسـم على اسـتعداد للتحمـل وخاصـة الحسالات غير الطبيعية او الجهد المضاعف المطلوب لان زيادة التدريب المستمر يؤدى الى تكيف الاجهزة على زيادة الجهد . م

r. النــواحى الفكريـة : يقوم الجمباز بدور مهم فحى تتميـة الجهاز العصبى ، اذ يتطلب مـن اللاعب التركيز الجيد فى اثثـاء الاداء الحركى وقبله ، فلاعب الجمباز يفكر قبل الاداء ويتصور كيف يستطيع اداء الحركة ، كذلك يفكر فى وضع الجسم على الجهاز وكيفية تفادى الاخطاء ومعالجتها ، ومن هذا يمكن تطوير رد الفعل البسيط والمعقد لاى اللاعبين ، وان تتمية التصور لدى لاعبى الجمبـاز تعد ذات اهميـة عظيمـة ، فاللاعب الجيد يجب ان يتصـور الجملـة الحركية بصورة عامة وحركات الربط بصورة جيدة قبل الاداء وتكون عبارة عن فيلم سينمائى مصور فى ذهن اللاعب . ع. التربيـة الثخصية : ينمى الجمباز لدى الفرد اهمية العلاقة النفسية وقيمتها عند الجماعـة وتاثيرهـاعلى سير التدريب الايجـابى والالهام مـع الاخرين فى تطوير مستوياتهم ، من خلال الجمباز نستطيع تتمية روح الشجاعة والمغامره بجوانبها الايجابية ، فلاعب الجمباز يجب عليه ان يقدم مهارات ذات صعوبة عالية وهذا بتطلب الثجاعة الكافية وروح المغامره وخاصـة الحركات الجديدة فى اثثاء التدريب ، ومن خلال العمل الجماعى ينمى الجمباز الثقة بالنفس ، ويعمق القيم الذاتية والسيطرة على روح الانانية ونقاط الضعف لاى الفرد .

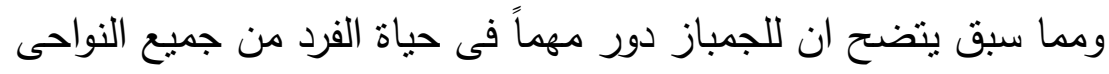


ثالثا المعوقات : ب (1)

هناك كثير من المعوقات التى تقف امام ممارسة وانتشار رياضـة الجمباز فىى صعيد مصر ويمكن تقسيمها على النحو التالى :-

\section{اولا النسبة للتخطيط}

- - عدم توفر الصالات والاجهزة باندية الصعيد ـ

-

- توضع البرامج من غير المتخصصين بالاتحاد .

\section{ثانيا بالنسبة للتوجيه}

- القائمين على اعمال المتابعة غير متخصصين •

- لاتوجد وسائل اتصال بين المدرب واللاعب تساعد على تقدم المستوى

ثالثا الرقابة

- ل التوجد معايير رقابة واضحة على مناطق الصعيد من قبل الاتحاد .

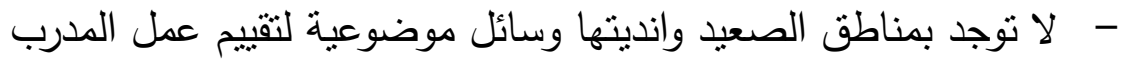

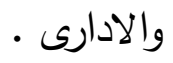

\section{رابعا بالنسبة للنواحى النفسية}

- سوء حالة الادوات والاجهزة المستخدمة فى التذريب باندية الصعيد

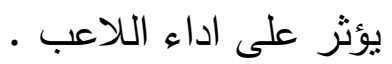

- - الجمباز من الانشطة التى لا بلقى لاعبيها اهتماما كافيا من المسئولين - الانشطة الجماعية لها جاذبية اكثر من الانشطة الفردية .

\section{خامسا بالنسبة للمدربين}

$$
\text { - قلة عدد المدربين المؤهلين بصعيد مصر - }
$$

- يقوم المدرب بالصعيد بتدريب اكثر من هيئة سعيا وراء زيادة الدخل .

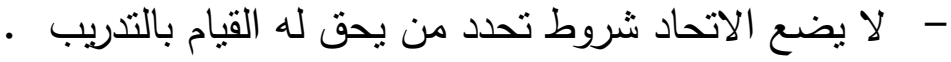




\section{سادسا بالنسبة للاعبين}

- مشاكل اللاعبين الاجتماعية تمنعهم من الالتزام فى التدريب مما يؤثر

$$
\text { على مستواهم }
$$

- تعارض وقت التدريب مع وقت الدراسة مما يعوق عملية التدريب اثتاء

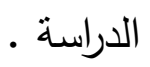

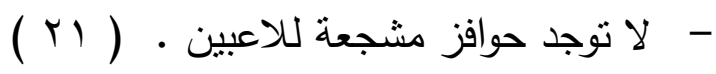

ثانياً الدراسات السابقة :

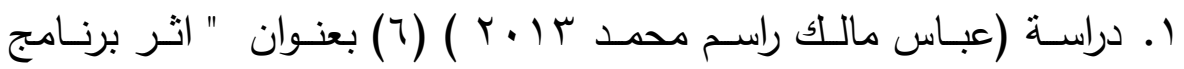

تدريبى مقترح على بعض المتغيرات البدنيـة والمهاريـة فى الجمباز لدى

طـلاب قسـم التربيـة الرياضـية فى جامعـة فلسـين التقنيـة خضـورى " ،

واستخدم الباحث المنهج التجريبى بتصميم المجموعتين التجريبية والضابطة

والقياسين القبلى والبعدى ، وتكونت عينة الدراسـة من ( جr ) طالبا من

طلاب المرحلة الاولى بقسم التربية الرياضية فى جامعة فلسطين التقنية

المسـلين لمسـاق جمباز ( ( ) ، وتم تقسيمهم الى مجموعتين احداهما

تجريبية وقوامها ( 11 ) طالبا والاخرى ضـابطة وقوامها ( 11 ) طالبا ،

وقد اظهرت نتائج الدراسـة ان البرنـامج التجريبى المقترح لله تاثير ايجابى

وفعـال فى تتميـة القدرات البدنيـة التى تـم تدريسـها ، كمـا ان البرنـامج

التـدريبى المقترح ذو فعاليـة فى تحسـين مسـتوى الاداء المهـارى للجهـل

الحركية على اجهزة الجمباز المدروسة .

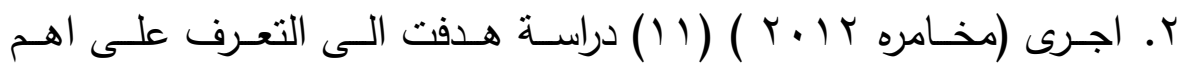

معوقات تدريس التربية الرياضية فى مديرية تربية وتعليم جنوب الخليل من

وجهـة نظـر المعلمـين ، وبيـان مـدى اخـتلاف هـه المعوقـات بـاختلاف 
متغيرات الدراسة : النوع الاجتماعى ، والمؤهل العلمى ، وسنوات الخبره ، ونوع المدرسـة ـ وقد استخدم الباحث المنهج الوصفى ، وطور استبانه لجمع البيانات ، ثم التحقق من صدقها وثباتها بالطرق التربوية والاحصائية المناسـبة ، وتكـون مجتمـع الدراسـة مـن جميـع معلمى التربيـة الرياضـية

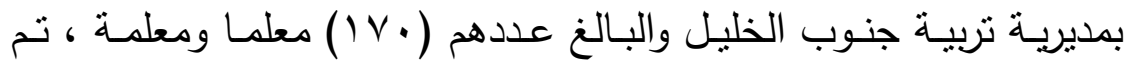
اختيار عينة عشوائية قوامها ( (T) معلما ومعلمة بنسبة هب\% ، واظهرت نتائج الدراسة ان معوقات تدريس التربية الرياضية جاءت بدرجة منوسطة ، كما اظهرت النتائج عدم وجود فروق ذات دلالـة احصـائية بين تقديرات افرادعينـة الددراسـة لمعوقات تدريس التربية الرياضية تعزى لمتغير النوع الاجتمـاعى ، والمؤهـل العلىـى ، وسـوات الخبـره ، ووجـود فـروق تعـزى هـ لمتغير المرحلة التعليمية لصالح المرحلة الثانوية . r. دراسـة ( ابو جامع ج · . r) (9) هدفت الى التعرف على معوقات تتفيذ الانشطة الرياضية المدرسية فى محافظة جنوب قطاع غزة من وجهة نطر مدرسى ومدرسات التربية الرياضية وقد اشتملت عينة الدراسة على (V0)

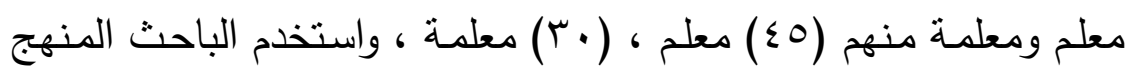
الوصفى مستخدما مقياس معوقات تتفيذ الانثطة الرياضية المدرسية ،

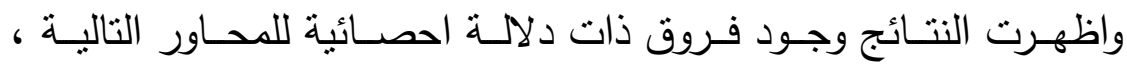
معوقات تتعلق بمجال تتفيذ درس التربية الرياضية معوقات تتعلق بالنشاط الاخلى ، معوقات تتعلق بالنشاط الخارجى .

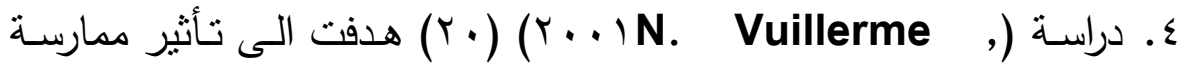
الجمبـاز علي شـكل الجسـم و التحقق مـن أن لاعبـي الجمبـاز يمتلكون 
أجسـاماً أكثر اسـتقراراً إلـي أي مـدي يتـأثر جسم اللاعب مـن ممارسـة

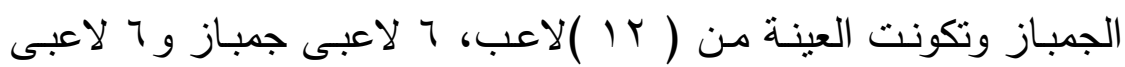
رياضـات أخري ، وكانت النتائج لاعب الجمباز لايه جسم أكثر استقرارا وتوازناً واستخلالاً لقدراته من لاعبي الرياضات الاخري . 0. دراسـة (المومنى سو 1991) ( ع) هدفت الى التعرف على معوقات ممارسـة رياضـة الجمباز من وجهة نظر معلمى التربية الرباضية لمرحلة التعليم الاساسى فى الاردن ، استخدم الباحث استبانة مكونة من •ـ فقرة موزعة على المنهاج ، الامكانات ، طريقة التدريس والمدرس ، تم اجراء الدراسـة على عينـة قوامها ؟ ؟ ـ معلماً ومعلمة ، توصلت الى ان جميع مجالات الاستبانة كانت معوقات بدرجة كبيرة ، حيث جاء ترتيب المعوقات حسب حدتها على النحو التـالى : الامكانـات يليـه المدرس ثم التدريس واخيـرا المنهاج ، كما اشـارت النتائج الى وجود فروق دالـة احصـائيا فى درجـة شيوع المعوقات تبعاً للخبره ، اضـافة الى فروق دالة احصائيا تعزى الى المؤهل العلمى لصـالح الدبلوم ، بينما لم يكن هناك فروق دالة احصائيا

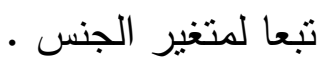

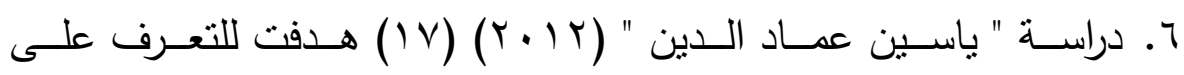
الصعوبات التى تواجه طلبة كلية التربية الرياضية فى جامعة الاقصى فى تعلم مساقات الجمباز ، تكونت عينة الدراسة من (7 (7) طالباً وطالبة ، تم اختيارهم بالطريقة العمدية من الطلبة الذين انهوا مساقات الجمباز ب, ؟, I

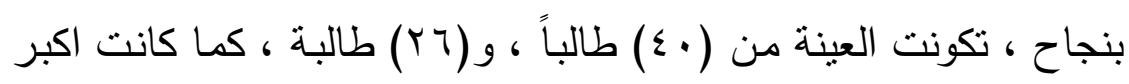
الصعوبات فى مجال الامكانات ، حيث وصلت الى (19,79) ثم تلاها 


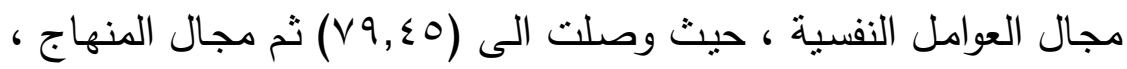

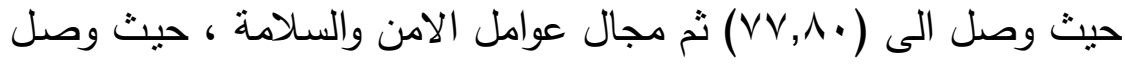

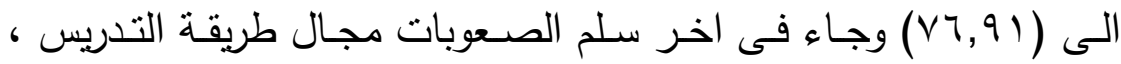

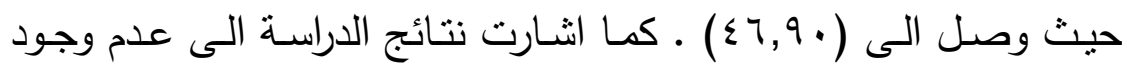
فروق ذات دلالـة احصـائية فـى درجـة الصـعوبات تعـزى لمتغير الجنس باسـتثناء الصـعوبات المتعلقـة بمجـال عوامـل الامـن والسـلامة ، وكانـــ

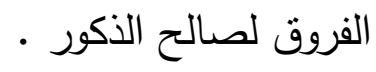
V. دراسـة " حمودة حسين الحساج " ( • • r) (r) هدفت الدراسـة الى وضـع تصور مقترح للتظلب على الصعوبات التى تواجه تدريس الجمباز بالمعاهد المتوسطة للتربية الرياضية فى الجمهوريـة العربيـة السورية ، وقد استخدم الباحث المنهج الوصفى باسلوب المسـح وذلك لمناسبته لطبيعـة البحث واهدافه وتكون مجتمع الدراسـة من ثـلاث فئات على النحو التالى / الفئة الاولى تم اختبارهم بالطريقة العمدية بالحصر الثامل من القائمين بتدريس مقرر الجمباز بالمعاهد المتوسطة للتربية الرياضية وعددهم (0 () ، الفئة الثانية تم اختيارها بالطريقة العشوائية من طلاب المعاهد المتوسطة للتربية الرياضية وعددهم (0بـ) ، الفئة الثالثة تم اختيارهـا بالطريقة العشوائية العمديـة وهى عبـارة عـن بعض خريجى المعاهـــ المتوسـطة للتريبـة الرباضـية وعددهم ( TVV) ) ، وكانت التوصـيات ضـرورة تطبيـق التصـور المقترح للتغلب على الصعوبات التى تواجه تدريس مقرر الجمباز •

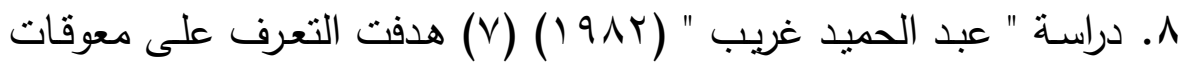
ياضة الجمباز للبنين بجمهورية مصر العربية للوقوف على اهم المعوقات 
التى تسبب عدم تقدم هذه الرياضـة بالقدر الكافى فى مصر ، واشتـلت عينة البحث على (ه9) خبيرا ومسئولا فى مجال الرياضـة و ( V ) لاعبا دوليا ، واستخدم الباحث المنهج المسحى عن طريق تصميم استبيان لجمع البيانات ، وقد اظهرت النتائج ان اهم المعوقات جاءب بالترنيب كما يلى : المكانـات-التخطيط- المـدرب- الاعـلام - الاداريـون - اوليـاء الامـور -

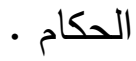

$$
\text { منهج البحث: :- }
$$

سوف تستخدم الباحثة المنهج الوصفى باحدى صوره المسحية نظراً لملاءمته

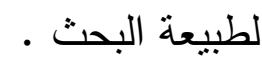

\section{مجتمع البحث :-}

اندية ومراكز الثباب بمحافظة أسوان محافظة اسوان

\section{عينة البحث :-}

اختيرت العينة من بعض اندية ومراكز الثباب بمحافظة أسوان وهم (مركز

شباب ادفو - نادى مصنع السكر بادفو - نادى التجديف - نادى اسوان الرياضى نادى التحرير - مركز شباب بدر - مركز شباب ساحة المدينة) المعالجات الاحصائية : المرئر تم استخدام المعالجات الاحصائية التالية : تم استخدام الاحصاء الوصفى لاستخراج المتوسطات الحسابية والانحرافات المعيارية الخاصة بفقرات ومتغيرات الدراسة . 
ادوات جمع البيانات : - البات

1- المقابلات الثخصية:

قامت الباحثة بعدل مقابلات شخصية مـع عدد من المسؤولين داخل الانديـة ومراكز الثـباب بمحافظة أسوان وذلك للتعرف على معوقات ظهور وانتشـار رياضــة الجمباز بمحافظة أسوان.

نتيجة المقابلة الثخصية:

توصلت الباحثة مـن خـلال المقابلات الثخصـية الى مجموعـة مـن العوامل التى تسببت فى عدم انتشار اللعبة فى صعيد مصر ومحافظة اسوان بشكل خاص: 1- اسباب خاصة بالممارسين. r- - اسباب خاصة بالامكانات المادية.

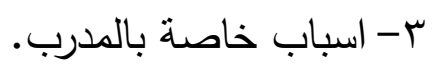
r-الاستبيانات المستخدمة بالبحث:

- استمارة تحديد محاور عدم انتشار رياضة الجمباز بمحافظة أسوان وعباراتها: تم تصميم (استبيان) لقياس معوقات ممارسـة رياضـة الجمباز فى صعيد مصر

\section{وفقا للخطوات التالية:}

ا. الاطلاع على عدد من المراجع العلمية والدراسات التى بحثت فى موضوع

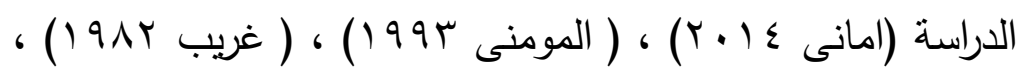

- (19^rSinger) 
r. استطلاع عدد من اراء اصحاب الاختصاص من اعضاء الهيئة التدريسية من اجل الاستماع لتوجيهاتهم حول مضمون الفقرات ومحاور معوقات ممارسة

$$
\text { رياضة الجمباز }
$$

بناء الاستبيانة بصورتها الاولية وجدول (1- r- r) يوضح ذلك.

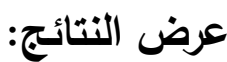

مـن خـلال تطبيـق الاسـتمارات على مجموعـة مـن الانديـة ومراكز الثـباب

$$
\text { ا توصلت الباحثة الى النتائج التالية: عرض نتائج التساؤل الاول: }
$$

والذي يـص على "مـا المعوقـات التهى تحـول دون ظهـور وانتشـار رياضـة

$$
\text { الجمباز فى صعيد مصر؟؟ }
$$




\section{جدول (๕)}

يوضح نتائج استمارة عبارات ومحاور عدم انتشار اللعبة بمحافظة أسوان (المحور

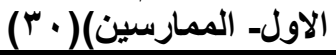

\begin{tabular}{|c|c|c|c|}
\hline المئوية & المقدرة & العبارة & 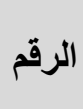 \\
\hline $9 \leq . \varepsilon$ & 1० & عدم رغبة الافراد فى ممارسة رياضة الجمباز & 1 \\
\hline ऍ^.^ & ro & عدم وجود دوافع لدى الافراد لممارسة رياضة الجمباز & r \\
\hline$\wedge \wedge . \wedge$ & $\Lambda$. & 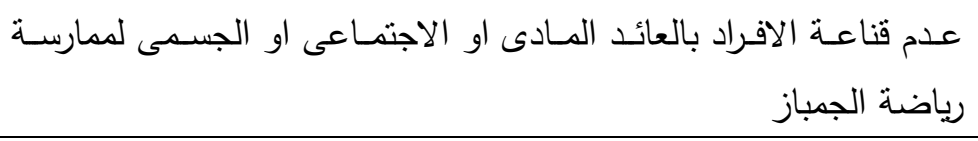 & r \\
\hline 97.7 & $\Lambda V$ & عدم وجود معلومات ومعارف لدى الافراد عن رياضة الجمباز & $\varepsilon$ \\
\hline $9 r .1$ & $\wedge \varepsilon$ & عدم وجود خلفية ايجابية لدى الافراد عن رياضة الجمباز & 0 \\
\hline$\varepsilon \varepsilon . \varepsilon$ & $\varepsilon$. & عـدم امتلاك الافراد لمهارات عمليـة سـابقة نسـاعد فى ممارسـة رياضــة & 7 \\
\hline$\wedge \vee \cdot \vee$ & $\vee 9$ & عدم امتلاك الافراد لمستوى اللياقة البدنية اللازم لمارسة رياضة الجمباز & V \\
\hline $1 \cdots$ & 9. & العادات والتقاليد بصعيد مصر من العوامل الاساية لعدم انتشار اللعبة & $\wedge$ \\
\hline NTH & Vo & الظروف المادية والمعيثية للأسره لا تسمح بممارسة رياضة الجمباز & 9 \\
\hline$\wedge \wedge . \wedge$ & $\wedge$ & مواعبد التدريب تمتد لساعات مما قد يعيق الملية التليمية لممارسين & 1. \\
\hline 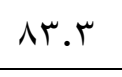 & vo & مواعيد البطولات قد لاتكون مناسبة للمارسين & 11 \\
\hline 0 . & $\leqslant 0$ & لا نتوجد بطـولات داخليـة مدـا يجعـل السـفر بشـكل مسـتمر مرهـق على & Ir \\
\hline
\end{tabular}

يتضـح مـن الجدول رقم (ع) يوضـح عبـارت المحسور الاول الممارسـين وقد

ارتضيت الباحثه نسبه • Vاكثر حيث تم استبعادوالعينه رقم

عدد العبارات التي تشير الى عدم انتشار اللعبه بالنسبه المحور الممارسين هى.

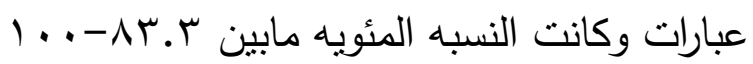


(•) (ندول

يوضح نتائج استمارة عبارات ومحاور عدم انتثار اللعبة بمحافظة أسوان (المحور

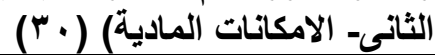

\begin{tabular}{|c|c|c|c|}
\hline المئوية & المقدرة & 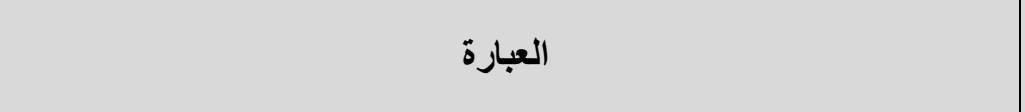 & 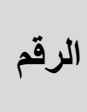 \\
\hline $9 \leqslant . \varepsilon$ & 10 & | عدم ملائمة الاجهزة المتوفرة مع ممارسة رياضة الجمباز & 1 \\
\hline 97.7 & $\wedge \vee$ & | عدم توافر العدد الكافى من الاجهزة والادوات لممارسة رياضة الجمباز & r \\
\hline 97.7 & $\wedge \vee$ & عدم توافر النوع الملائم من الاجهزة والادوات اللازمة لممارسة رياضة الجمباز & r \\
\hline $1 \cdots$ & 9. & عدم توافر وسائل الامن والسلامة فى الاجهزة والادوات المتوفرة & $\varepsilon$ \\
\hline $1 \ldots$ & 9. & | عدم وجود صالات خاصة بممارسة راضة الجمباز & ○ \\
\hline$\circ$. & 纟o & | عدم توافر وسائل تعليمية توضيحية & 1 \\
\hline 97.7 & $\wedge \vee$ & عدم وجود مخصصات مالية تدعم رياضة الجمباز & v \\
\hline $1 \ldots$ & 9 . & بمحافظة اسوان لاند من وزارة الشباب والرياضة لانتشار رياضة الجمباز & $\wedge$ \\
\hline $1 \ldots$ & 9 . & لا لاباضة الجمباز اهتمام من الاتحاد الخاص باللعبة بنشر ادوات واجهزة & 9 \\
\hline TV & TV & لا توجد صيانة دورية للأدوات والاجهزة & 1. \\
\hline $1 \cdots$ & 9. & لا توجد صالات مغلقة لتناسب رياضة الجمباز . & 11 \\
\hline $9 \varepsilon . \varepsilon$ & 10 & التكلفة المادية الكبيرة للمشاركة فى البطولات التى يحددها الاتحاد & ir \\
\hline \multicolumn{4}{|c|}{ 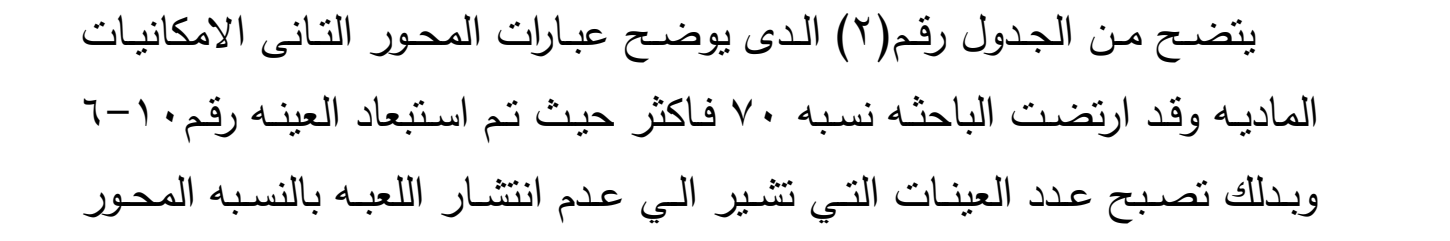 } \\
\hline
\end{tabular}




\section{جدول (7) (7)}

يوضح نتائج استمارة عبار ات ومحاور عدم انتشار اللعبة بمحافظة أسوان

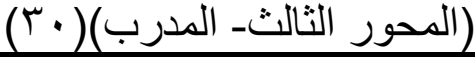

\begin{tabular}{|c|c|c|c|}
\hline المئويه & المقدرة & 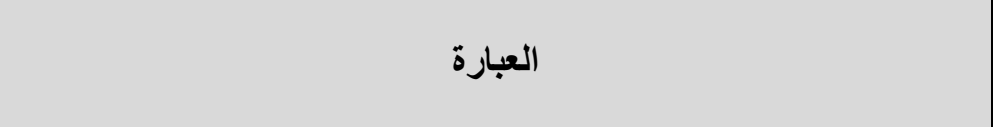 & 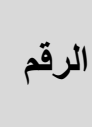 \\
\hline $9 \varepsilon . \varepsilon$ & 10 & خبرات المعلم العلمية غير كافية لتدريب مهارات الجمباز. & 1 \\
\hline 91.1 & Ar & معلومات المدرب النظرية غير كافية للتدريب. & r \\
\hline$\wedge \uparrow .7$ & vA & لا توجد خبرات سابقة لتدريب رياضة الجمباز . & r \\
\hline$\wedge \wedge . \wedge$ & $\wedge$. & لا يمتلك المدرب لميل والرغبة في تدريب رياضة الجمباز & $\varepsilon$ \\
\hline$\varepsilon \varepsilon . \varepsilon$ & $\varepsilon$ & رياضة الجمباز التـريب كبيرة لارجـة عدم رغبـة المسربين فى تلدريب & 0 \\
\hline 97.7 & $\wedge \vee$ & لا تحتاج رياضة الجمباز الى جه بلنى كبير مما يجعل المدرب & 7 \\
\hline $9 \varepsilon . \varepsilon$ & 10 & لا توجد دورات تدريبية بشكل خاص لرياضة الجمباز & v \\
\hline 97.7 & $\Lambda 7$ & عدم اهتمام اتحاد اللعبة بعمل دورات تدريبية فى صعييد مصر & $\wedge$ \\
\hline $0 \vee .7$ & or & لا توجد خبرة لدى المدريين فى استخدام الادوات الحديثة فى & 9 \\
\hline $1 \cdots$ & 9. & لا يوجد مناطق تابعة للاتحاد للإشراف ومتابعة انتشار اللعبة & $1 \cdot$ \\
\hline $9 \varepsilon . \varepsilon$ & 10 & لا يوجد دخلل مادى للمدرب يجعلة متفرغاً للتدريب & 11 \\
\hline r.tr & ov & المدرب لا يتابع التطور الفنى للاعبين & ir \\
\hline$\varepsilon \varepsilon . \varepsilon$ & $\varepsilon$. & عدم تتفيذ الخطة الموجودة من قبل الاتحاد او النادى بدقة & r \\
\hline
\end{tabular}


وتبصح عددالعينات التى تشير الى عدم انتشار اللعبه بالنسبه المحور المدرب هى

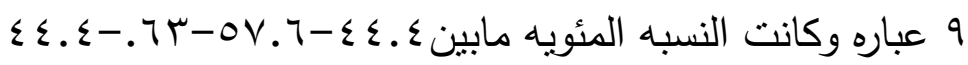
الاستتناجات:

فى ضوء تساؤلات البحث ومن خلال عرض النتائج يمكن ان نستتنج الاتى: 1- اكثر الاسباب فى عدم انتشار رياضة الجمباز والخاصـة بمحور الممارسين كانت العبارة رقم (^) والتى تنص على " العـادات والتقاليد بصعيد مصـر من العوامل الاساية لعدم انتشار اللعبة "حيث سجلت نسبة مئوية ( . ( (\%). r- اكثر الاسباب فى عدم انتشار رياضـة الجمباز والخاصة بمحور الامكانات الماديه كانـت العبارة رقم (ع-0-1-9) والتـى تنص على " عدم تـوافر وسـائل الأمـن والسـلامة في الاجهزة والادوات المتوفرة - عدم وجـود صـالات خاصـة بممارسـة راضة الجمباز - لا يوجد دعم من وزارة الثباب والرياضة لانتشار رياضـة الجمباز بمحافظة اسوان - لا يوجد اهتمام من الاتحاد الخاص باللعبة بنشر ادوات واجهزة رياضة الجمباز بالصعيد"حيث سجلت نسبة مئوية ( . . (\%). r- اكثر الاسباب فى عدم انتشار رياضـة الجمباز والخاصـة بمحور المدرب كانت

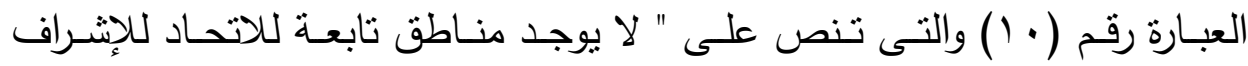
ومتابعة انتشار اللعبة "حيث سجلت نسبة مئوية ( . ( \%).

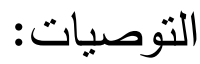
فى ضوء ما توصلت اليه الباحثه من استتناجات فإنها توصي بالاتى: 1- عمل دورات تدريبية لنقل المدربين فى رياضه الجمباز • r- عمل مناطق فى محافظات الصعيد تابعه للاتحاد المصرى للجمباز • r- عمل بعض البطولات فى محافظات الصعيد وذلك تتجيعاً للاطفال واولياء الامور

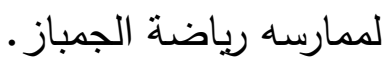


ع - اهتمام الاندية بتوفير بعض الامكانات والاجهزة الخاصه برياضه الجمباز • 0- تقيليل قيمه الاشتراكات الماديه فى البطولات الخاصده بالاتحاد لمحافظات الصعيد لتشجيع الانديه على نشر اللعبه.

$$
\text { المراجع }
$$

$$
\text { اولا:المراجع العربية :- }
$$

1. احمد يوسف : اساليب منهجية وتدريب الجمباز ، دار المعارف ، القاهرة V99

r. امـانى ماجد القرالـه : معوقـات تـدريس منهاج الجمبـاز مـن وجهة نظـر مدرسى ومدرسات التربية الرياضية فى مديرية تربية لواء المزار الجنوبى ، رسالة ماجستير

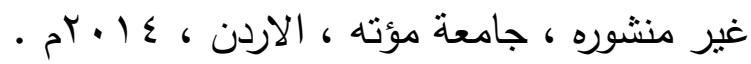
ץ. حمودة حسين الحاج : تصور مقترح للتغلب على الصسوبات التى تواجه تدريس مقرر الجمبـاز فى المعاهـد المتوسـة للتربيـة الرياضـية فـى الجمهوريـة العربيـة السورية ، اتحاد مكتبات الجامعات العربية ، رسالة ماجستير غير منشورة ، مصر $\cdot a_{r} \cdot 1 \cdot 6$

ء. زياد على عكاشة المومنى : معوقات ممارسة رياضة الجمباز لتلاميذ مرحلة التعليم الاساسى من وجهة نظر مدرسى التربية الرياضية ، رسالة ماجستير غير منشورة ،

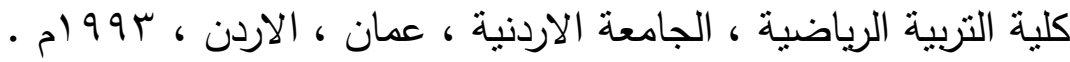
ه. عادل عبد البصبر : النظريات والاسس العلمية فى تدريب الجمباز ، الجزء الاول ، دار الفكر العربى ، القاهرة ، 991 ام • 7. عباس ماللك راسم محمد : اثز برنامج تدريبى مقترح على بعض المتغيرات البدنية والمهارية فى الجمباز لدى طلاب قسم التربية الرياضية فى جامعة فلسطين التقنية | خضورى ، رسالة ماجستير غير منشورة ، كلية الدراسات العليا ، جامعة النجاح

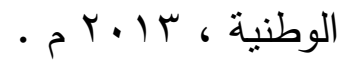


V. عبد الحميد غريب : معوقات رياضة الجمباز للبنين بجمهورية مص العربية ،

رسالة ماجستير غير منشورة ، كلية التربية الرياضية للبنين ، القاهرة بر9 ام ـ

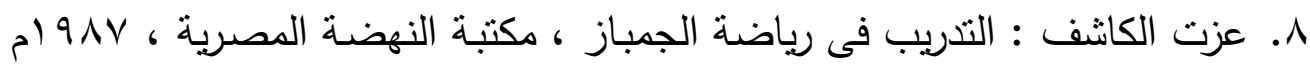

9 ـ فتحى ابو جامع : معوقات تنفيذ الانشطة الرياضية المدرسية فى محافظات جنوب

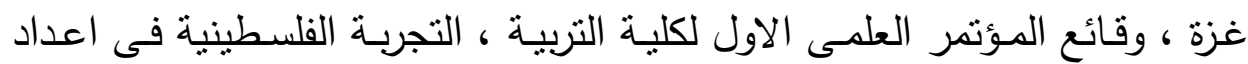
المناهج الواقع والتطلعات ، المجلد ب ، جامعة الاقصى ، غزة ، 7 ، . بام • • 1 ـ فوزى يعقوب عادل عبد البصير : النظريات والاسس العلمية فى تدريب الجمباز

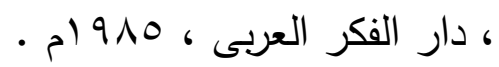

11. كمـال مخامره : اهم معوقات تدريس التربيـة الرياضية فى مدارس مديريـة تربيـة

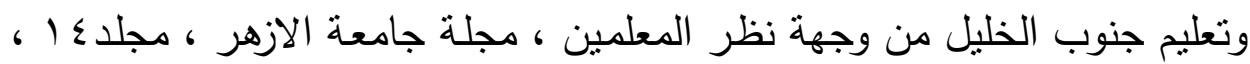

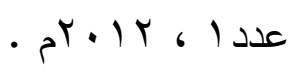

r ا. محمد ابراهيم شحاته : اسس تعليم الجمباز ، دار الفكر العربى ، كلية التربية

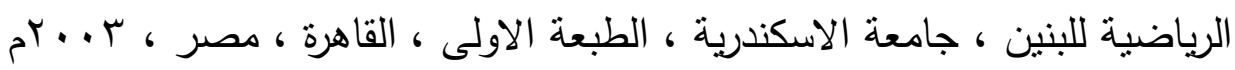

ب ا. محمد ابوالحمد عبد الوهاب : اساسيات الجمباز الفنى الحديث ، الطبعة الاولى ،

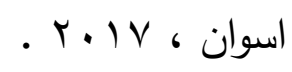

ع ا ـ محمد سعيد دخيل الله : دراسة تحليلية للاسباب المؤدية لحدوث الاصابات الرياضية لدى طلبة مساقات الجمباز فى كليات التربية الرياضية فى الجامعات

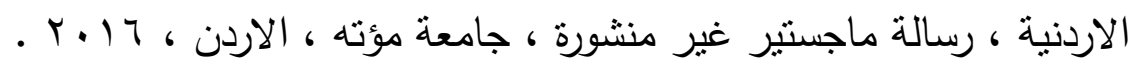
1 ـ معيوف حنتوش ، محمد عامر : المدخل فى الحركات الاساسية لجمباز الرجال، دار الكتب للطباعة والنشر ، بغداد 911 ام .

7 ا ـ معيوف ذنون حنتوش : المبادئ الفنية والتعليمية للجمباز والتمارين البدنية ، وزارة التربية والتعليم والبحث العلمى ، جامعة الموصل ، العراق ، 910 ام . 
V V . ياسين عماد الدين : الصعوبات التى تواجه طلبة كلية التربية البدنية والرياضبة فى تطبيق الجوانب العلمية لمساقات الجمباز بجامعة الاقصى ، رسالة ماجستير غير منشورة ، الجامعة الاسلامية ، غزة ، فلسطين ، ب ا • بام . ثانيا:المراجع الاجنبية :-

18 .Candian gymnastc federation : coaching certiffiction manul, vanier city ,Ontario m 1996.

19 .Singer:the learning of motor skills, macmillan publishing co, in new york, 1982.

20 . Vladimir Liakh, Wladyslaw Zmuda ,Zbigniew Witkowski The Prognostic Value of Coordination Motor Ability ( CMA ) Indices in the Evaluation of Development of Soccer Players Aged 16-19, ( A 2 - Year Observation) . Human Movement, No. 1 , Supplement Part 2 , Poland, 2001.

$$
\text { ثنالثا: الثبكة العنكبوتية ( الانترنت ) }
$$

21. www.gymnastic.com21 